\title{
WOUND HEALING: TENSIONAL FACTOR PATHOMECHANISM IN OCCURANCE OF ABNORMAL SCAR
}

\author{
Gerardo AK Laksono ${ }^{1)}$, Paul L Tahalele ${ }^{2)}$, Jose L Anggorwasito ${ }^{3)}$, \\ HYL Wihastyoko ${ }^{4)}$
}

\begin{abstract}
Wound healing is a series of biophysiological processes, beginning with tissue injury, and ending with repairs from the wound tissue itself to a complete state consisting of several phases including inflammation, proliferation and remodeling. Every process of wound healing always leaves a scar. Hypertrophic and keloid is a product of abnormal wound healing. This abnormal scar formation is influenced by several factors, one of which is the wound stress. A tension that is too large in a wound will cause a hypoxic state in the wound itself. This hypoxic state will cause recurrent inflammation which leads to abnormal scar formation. One of abnormal scars formation prevention is reduction in wound tension. Reduction in wound tension reduce the inflammation process.
\end{abstract}

\footnotetext{
${ }^{1)}$ Student of Faculty of Medicine, Widya Mandala Catholic University Surabaya, South Kalisari 1 Surabaya

${ }^{2)}$ Surgery Department, Faculty of Medicine, Widya Mandala Catholic University Surabaya, South Kalisari 1 Surabaya

${ }^{3)}$ Dermatology and Venereology Department, Faculty of Medicine, Widya Mandala Catholic University Surabaya, South Kalisari I Surabaya

4)Plastic and Reconstructive Surgery Department Brawijaya University - Saiful Anwar Hospital Malang.
} 


\section{Wound healing}

Wound healing is a series of biophysiological processes, beginning with tissue injury, and end with the complete repair of the wound tissue itself. This wound healing process consists of three interrelated and overlapping phases including 1 . Inflammation; 2. Proliferation; 3. Remodeling (1)

\section{Inflammatory Phase}

The inflammatory phase occurs four days after injury. This inflammatory phase is described as rubor et tumor cum calore et dolore. $^{(2)}$ This inflammatory response can be distinguished into a vascular response and cellular response ${ }^{(3)}$. The vascular response that comes out during bleeding is direct vasoconstriction in the blood vessels to minimize blood loss. Another vascular response is the formation of fibrin clot. ${ }^{(4)}$ Proinflammatory cytokines and growth factors such as tumour growth factor- $\beta$ (TGF- $\beta$ ), platelet derived growth factors (PDGF), fibroblast growth factor (FGF) and epidermal growth factor (EGF) will be released by Fibrin clot and surrounding injury tissue. After bleeding can be controlled, inflammatory cells will migrate to the wound (chemotaxis) and continue with cellular response to the inflammatory phase. ${ }^{(1,5)}$ This cellular response begins when there is an influx of leukocytes, neutrophils and monocytes in the injured area. These monocytes will later become macrophages.
These neutrophils and monocytes migrate to the wound area because of the chemotaxic factor released during the vascular response (hemostasis) by mast cells. ${ }^{(3)}$ Neutrophils phagocytes microorganisms in the wound and act as the first line of defense in preventing infection. ${ }^{(4)}$ Macrophages have an important role in the process of wound healing. Macrophages are phagocytic monocytes that are responsible for recognizing foreign microorganisms in the body, initiating of the inflammatory phase, and tissue restoration. ${ }^{(6)}$ Macrophages can be called the initial triggers of the proliferation phase in the wound healing process. ${ }^{(5)}$

\section{Proliferation Phase}

The proliferation phase occurs after the inflammatory phase and overlaping with each other. This proliferation phase occurs for 4-21 days in acute wounds, depending on the size of the wound and the patient condition. ${ }^{(7)}$ This proliferation phase is characterized by the initiation of angiogenesis process, tissue granulation formation, wound contraction, epithelial proliferation, and reepithelialization. $^{(8)}$ In reparative dermis condition during the proliferation phase, many cells are found such as fibroblast cells, pericytes keratinocytes and endothelial cells. In this proliferation phase, fibroblasts migrate. This fibroblast migration is influenced by the activity of factors such as TGF- $\beta$ and PDGF, which are released by inflammatory cells and platelets. ${ }^{(9)}$ Fibroblast 
cells will secrete collagen which will then induce regeneration from the dermal. On the basis of the wound area, fibroblasts also produce glycosaminoglycans, and proteoglycans as the main components of extra cellular matrix fluids. Pericytes cells are responsible for regenerating the outer part of the capillaries, and endothelial cells. This process is called angiogenesis.

\section{Remodeling Phase}

The last phase of the wound healing process is the remodeling phase. This phase can continue up to several years during the wound healing process. The remodeling phase begins when extracellular matrix fluid has been formed. ${ }^{(10)}$ Microscopic findings show that in this phase there is a decrease in the number of fibroblasts, vascular occlusion, and hardening of collagen fibers. The production and degradation of collagen that takes place continuously during the remodeling phase has a dominant effect in wound maturation. Production and degradation balance each other, and normally there is no major difference in the amount of production and degradation of collagen. ${ }^{(11)}$

\section{Pathogenesis of Abnormal Scars}

Abnormal scarring results from prolongation and abnormalities in the wound healing process. This causes excessive production of fibroblasts and collagen deposition $^{(12)}$ This excessive collagen deposition may occur because of three possibilities: 1. Increased synthesis without being accompanied by increased degradation; 2. The synthesis and degradation of collagen both increase, but the increase in collagen synthesis is higher than the degradation; 3. Normal collagen synthesis but with decreased degradation. Abergel's study reported that keloid scar was found to accumulate collagen with proline hydroxylase enzyme activity 1420 times greater than normal scar and 3 times when compared with hypertrophic scarring and keloid collagenase activity which increased 14 times normal scar and 4 times hypertrophic scar . ${ }^{(13)}$

Prolonged inflammatory phase and the presence of an immune response during the wound healing process are factors in the formation of hypertrophic and keloid scars. The immune response that comes out during the inflammatory process, especially the expression of Th2 with the production of IL4, IL-5, IL-10, IL-13 are much associated with fibrogenesis, while Th1 and CD41 are mostly associated with fibrosis through the production of interferon and IL - 12. ${ }^{(14)}$

Not only during the inflammatory phase, recent studies have shown the involvement of growth factors in hypertrophic and keloid scar formation during the fibrogenic phase. ${ }^{(15)}$ When compared to normal fibroblasts, hypertrophic and keloid scar fibroblasts show an increased number of receptor growth factors, especially in TGF- $\beta$ and PDGF. ${ }^{(16)}$ TGF- $\beta$ has the effect of chemotaxis on fibroblasts to the wound area. 
TGF- $\beta$ also has a role for fibroblast proliferation and collagen production.

Normally, when the wound healing process is complete, the activity of TGF- $\beta$ also automatically stops. However, hypertrophic scars and keloids occur have abnormalities in the autocrine signaling mechanism resulting in overproduction and poor regulation of TGF- $\beta$ (Figure 1). Transforming growth factor- $\beta 1$ (TGF $\beta 1)$ and TGF $\beta 2$ are the most important stimulators of collagen and proteoglycan synthesis and affect extracellular matrix fluid, not only by stimulating collagen production but also preventing destruction. On the other hand, TGF $\beta 3$ has a function that is opposite to TGF $\beta 1$ and TGF $\beta 2$, which is reducing connective tissue deposition. Studies also show that in hypertrophic and keloid scarring, over-expressions of TGF $\beta 1$ and TGF $\beta 2$ are found followed by decreased expression of TGF $\beta 3 .^{(17,18,19)}$

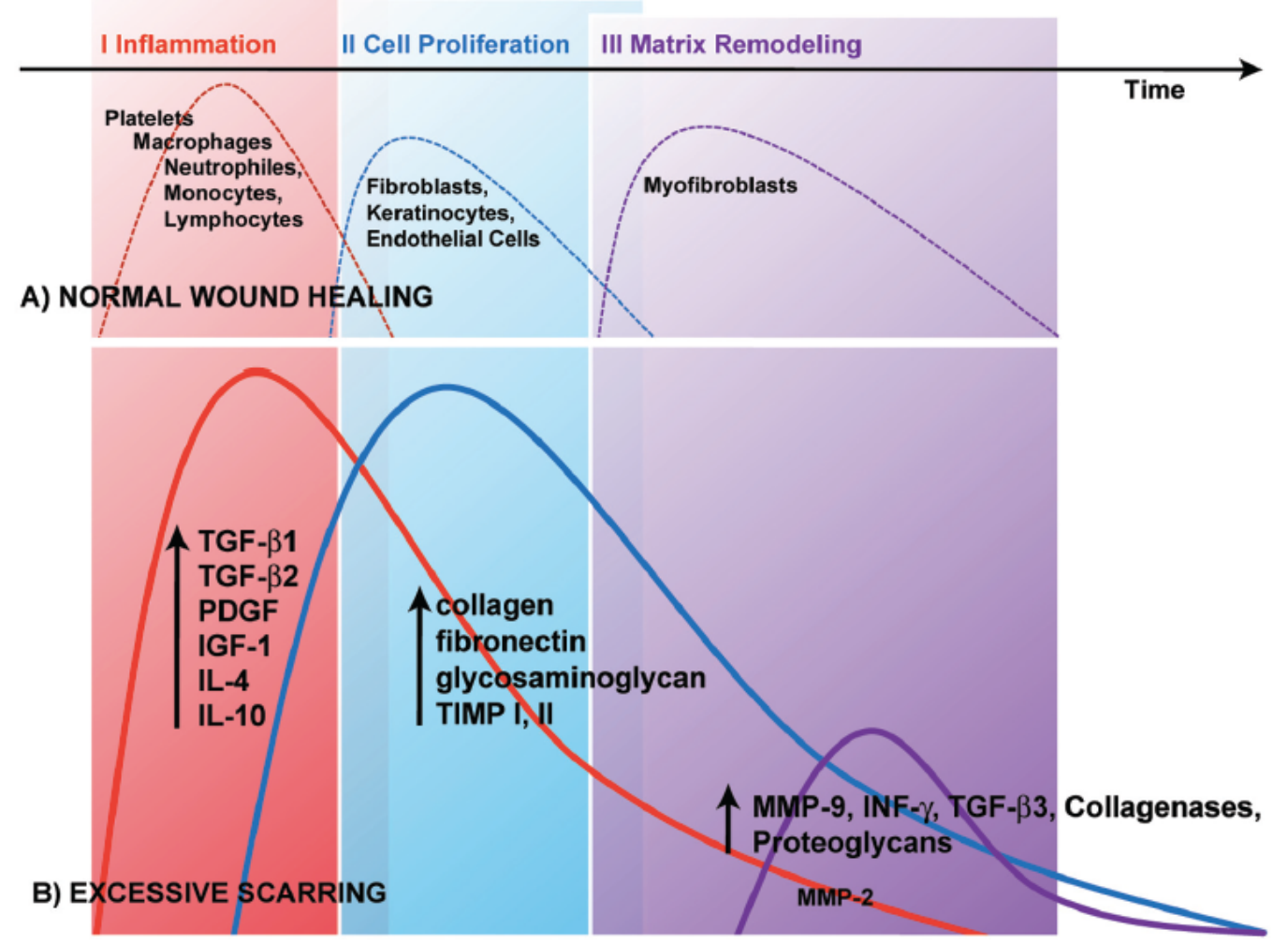

Figure 1. Schema of the Abnormal Scar Process: A. Normal Wound Healing, B. Excessive Scaring ${ }^{(20)}$

\section{Wound Tension and Scar Quality}

The concept of tension on the skin has been introduced more or less 200 years ago. Human body consists of a skeletal bone, which is covered by the skin. This covering skin must be elastic, so that it can return to its original shape when stretching during activity. Mechanically, the skin must be strong and flexible. ${ }^{(21,22)}$ Tension on the skin, depending on the movement of the skeleton 
below, and the high tension of the skin in certain anatomical regions are often associated with abnormal scarring. Langer's line is best known to clinicians in determining the skin tension lines of the human body (Figure 2). ${ }^{(23)}$ The stress lines on this skin follow collagen collections that are present in the dermis. Parts of the skin with a high skin

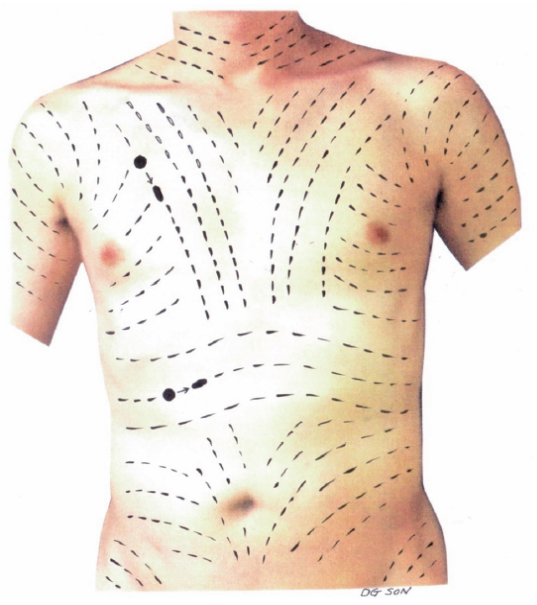

Figure 2. Langer Line and Resting Static Tension Line ${ }^{(22)}$ tension include the chest, shoulders, extremity region, and face. There are also parts of the skin that do not have high tension, which is often referred to as the relaxed skin tension line (RSTL). This line is commonly used by clinicians to make excision and incision on the skin to reduce the chance of abnormal scarring $^{(24)}$

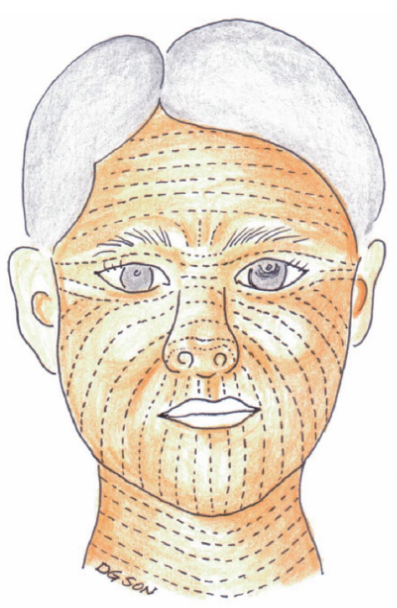

One factor of the occurrence of abnormal scarring is delayed wound healing caused by prolonged inflammation. ${ }^{(25)}$ Inflammation that is higher in the wound area results in greater tension as well, this causes blood vessel overgrowth, nerve overgrowth, cell proliferation and matrix hyperproduction (Figure 3). Direct reduction of stress on the wound will also increase the supply of oxygen to the wound and accelerate the wound healing process ${ }^{(26)}$. The absence of adequate oxygen supply will make the wound hypoxic. This hypoxic condition will stimulate the body to release HIF-1 as a compensation mechanism. This HIF-1 can induce inflammatory processes and angiogenic processes. HIF-1 affect the inflammatory response by changing metabolic functions to glycolysis. (HIF-1) also has a function as a regulator of macrophage activity during the inflammatory process. HIF-1 has an important function in the differentiation of myeloid cells into monocytes and macrophages. ${ }^{(27)}$ HIF-1 also has a stimulus effect in the process of angiogenesis. HIF-1 has an effect on increasing VEGF expression which is a potent angiogenic factor during the angiogenesis process. ${ }^{(28)}$ The aim of stress reduction is to prevent of overexpression of this HIF-1. 


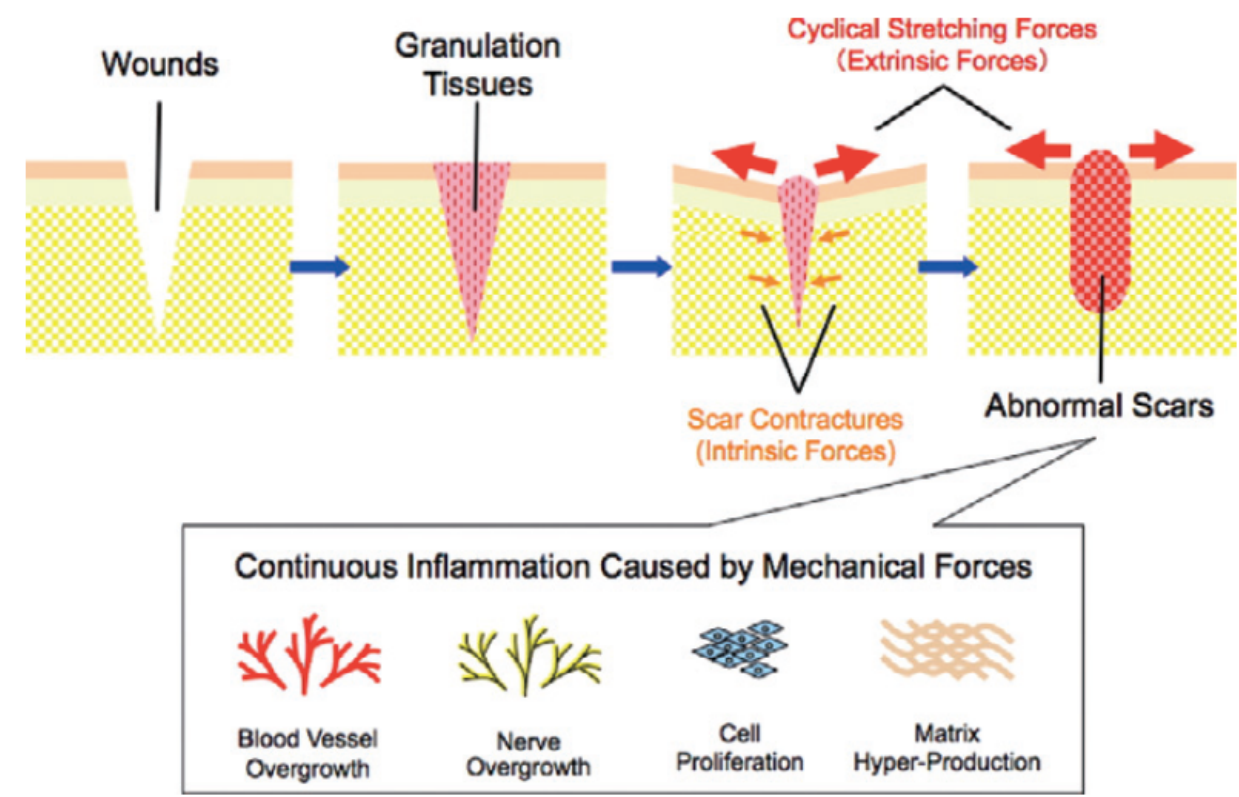

Figure 3. Skin Tension Schematic and the Abnormal Scratch ${ }^{(24)}$

\section{REFERENCE}

1. Gosain, A., Dipietro, M. D. L. A. \& $\mathrm{Ph}, \mathrm{D}$. Aging and Wound Healing. World J. Surg. 28, 321-326 (2004).

2. Diegelmann, R. F. Wound healing: an overview of acute, fibrotic and delayed healing. Front. Biosci. 9, 283 (2004).

3. Li, J., Chen, J. \& Kirsner, R. Pathophysiology of acute wound healing. Clin. Dermatol. 25, 9-18 (2007).

4. Keast, D. H. \& Orsted, H. The basic principles of wound care. Ostomy. Wound. Manage. 44, 24-8, 30-1 (1998).

5. Guo, S. \& DiPietro, L. A. Critical review in oral biology $\&$ medicine: Factors affecting wound healing. $J$. Dent. Res. 89, 219-229 (2010).
6. Willenborg, S. et al. Genetic Ablation of Mast Cells Redefines the Role of Mast Cells in Skin Wound Healing and. Soc. Investig. Dermatology 134, 2005-2015 (2014).

7. Landén, N. X., Li, D. \& Ståhle, M. Transition from inflammation to proliferation: a critical step during wound healing. Cell. Mol. Life Sci. 73, 3861-3885 (2016).

8. Flanagan, M. The physiology of wound healing. J. Wound Care 9, 25-26 (2000).

9. Velnar, T., Bailey, T. \& Smrkol, J. The Wound Healing Process: an Overview of the Cellular and Molecular Mechanisms. J. Int. Med. Res. 37, 1528-42 (2009).

10. Cristina, A. \& Gonzalez, D. O. 
Wound healing - A literature

review*. An Bras Dermatol 91, 614-620 (2016).

11. Li, B. \& Wang, J. H. . Fibroblast and Myofibroblast in Wound Healing: Force Generation and Measurement. J Tissue Viability 4, 108-120 (2012).

12. Huang, C., Murphy, G. F., Akaishi, S. \& Ogawa, R. Keloids and hypertrophic scars: Update and future directions. Plast. Reconstr. Surg. 1, (2013).

13. Perdanakusuma, D. Penanganan Parut Hipertrofik dan Keloid. (Airlangga University Press, 2017).

14. Wynn, T. A. Fibrotic Disease And The Th1/Th2 Paradigm. Nat. Rev. Immunol. 4, 583-294 (2004).

15. Wolfram, D., Tzankov, A., Pülzl, P. \& Piza-Katzer, H. Hypertrophic scars and keloids - A review of their pathophysiology, risk factors, and therapeutic management.

Dermatologic Surg. 35, 171-181 (2009).

16. Yoshimoto, H. et al.

Overexpression of insulin-like growth factor-1 (IGF-I) receptor and the invasiveness of cultured keloid fibroblasts. Am. J. Pathol. 154, 883-889 (1999).

17. Bock, O. et al. Aberrant expression of transforming growth factor $\beta-1$ (
TGF $\beta-1$ ) per se does not

discriminate fibrotic from nonfibrotic chronic myeloproliferative disorders. J. Pathol. 205, 548-557 (2005).

18. George J, Y. Y. et al. Mast Cells Are Required in the Proliferation and Remodeling Phases of Microdeformational Wound Therapy. Plast. Reconstr. Surg. 128, 649-658 (2011).

19. Wulff, B. C. \& Wilgus, T. A. Mast cell activity in the healing wound : more than meets the eye? Exp.

Dermatol. 22, 507-510 (2013).

20. Gauglitz, G. \& Korting, H.

Hypertrophic Scarring and Keloids:

Pathomechanism and current emerging treatment strategies. Mol. Med. 17, 113-125 (2011).

21. Artuc, M., Steckelings, U. M. \& Henz, B. M. Mast Cell \pm Fibroblast Interactions: Human Mast Cells as Source and Inducers of Fibroblast and Epithelial Growth Factors. Soc. Investig. Dermatology 391-395 (2002).

22. Son, D. \& Harijan, A. Overview of surgical scar prevention and management. J. Korean Med. Sci. 29, 751-757 (2014).

23. Suarez, E. et al. Skin equivalent tensional force alters keloid fibroblast behavior and phenotype. 
Wound Repair Regen. 22, 557-568

(2014).

24. Ogawa, R. et al. Clinical

Applications of Basic Research that

Shows Reducing Skin Tension

Could Prevent and Treat Abnormal

Scarring: The Importance of

Fascial/Subcutaneous Tensile

Reduction Sutures and Flap Surgery

for Keloid and Hypertrophic Scar

Reconstruction. J Nippon Med Sch

78, 68-76 (2011).

25. Jeong, W. et al. Scar prevention and enhanced wound healing induced by polydeoxyribonucleotide in a rat incisional wound-healing model. Int. J. Mol. Sci. 18, 1-12 (2017).

26. Balin, A. K. \& Pratt, L. Oxygen Modulates the Growth of Skin Fibroblasts. Soc. Vitr. Biol. 38, 305310 (2016).

27. Hong, W. X. et al. The Role of Hypoxia-Inducible Factor in Wound Healing. Adv. Wound Care 3, 390399 (2014).

28. Ruthenborg, R. J., Ban, J. J., Wazir, A., Takeda, N. \& Kim, J. W. Regulation of Wound Healing and Fibrosis by Hypoxia and HypoxiaInducible Factor-1. Mol. Cells 37, 637-643 (2014). 